\title{
Preliminary results of a new global ocean reanalysis
}

\author{
WANG DongXiao $^{1}$, QIN YingHao ${ }^{1,2 *}$, XIAO XianJun $^{3}$, ZHANG ZuQiang $^{3}$ \& WU FengMin ${ }^{4}$ \\ ${ }^{1}$ State Key Laboratory of Tropical Oceanography, South China Sea Institute of Oceanology, Chinese Academy of Sciences, \\ Guangzhou 510301, China; \\ ${ }^{2}$ Graduate University of Chinese Academy of Sciences, Beijing 100049, China; \\ ${ }^{3}$ National Climate Center, Beijing 100081, China; \\ ${ }^{4}$ Nanjing University of Information Science and Technology, Nanjing 210044, China
}

Received January 5, 2012; accepted April 5, 2012; published online May 30, 2012

\begin{abstract}
Using a new global ocean reanalysis of the second generation Global Ocean Data Assimilation System of the Beijing Climate Center (BCC_GODAS2.0) spanning the period 1990-2009, we firstly quantify the accuracy of BCC_GODAS2.0 in representing the temperature and salinity by comparing with OISST and SODA data. The results show that the assimilation system may effectively improve the estimations of temperature and salinity by assimilating all kinds of observations, especially in the equatorial eastern Pacific. Moreover, the root mean square errors of monthly temperature and salinity are respectively reduced by $0.53^{\circ} \mathrm{C}$ and 0.28 psu, compared with the model control simulation results. Then, the applicability of this ocean reanalysis for sea surface temperature (SST) anomaly variability in the tropical Pacific is evaluated with the observational HadISST data. The NINO3 index of the new reanalysis shows a good agreement with that of HadISST, with a correlation of 93.6\%. Variations in SST from BCC_GODAS2.0 are similar to those obtained from HadISST data along the equator, showing the major large zonal-scale features such as the strong magnitude of seasonal cycle. The amplitude of SST anomaly standard deviation in the equatorial eastern Pacific is also closer to observations (HadISST) than NCEP GODAS does. Besides, the first two leading empirical orthogonal function (EOF) modes of the monthly SST anomalies over the tropical Pacific region are explored. The EOF1 pattern of BCC_GODAS2.0 captures a traditional El Niño pattern, which improves magnitudes of the positive SST anomaly in the cold tongue of the eastern Pacific. The EOF2 pattern exhibits a El Niño Modoki pattern. Comparatively, the EOF2 pattern of BCC_GODAS2.0 extends more strongly toward the subtropics. It also overcomes the problem that negative loadings are confined in the narrow equatorial eastern Pacific. Consequently, the magnitude and spatial distribution of the leading EOF patterns of BCC_GODAS2.0 are well consistent with those of HadISST.
\end{abstract}

BCC_GODAS2.0, temperature, salinity, EOF, EI Niño, El Niño Modoki

Citation: Wang D X, Qin Y H, Xiao X J, et al. Preliminary results of a new global ocean reanalysis. Chin Sci Bull, 2012, 57: 3509-3517, doi: 10.1007/s11434$012-5232-\mathrm{x}$

In recent decades, the techniques of satellite remote sensing have been widely applied in ocean observation systems, which are now available to provide plenty of surface marine data, including satellite altimetry, satellite remote sensing of SST and surface wind stress etc. Compared with the traditional types of in situ data (drifting buoys, moored buoys and ships), the remote sensing data has the advantage of being extremely homogeneous with high spatial and temporal resolution and being available in almost real time.

*Corresponding author (email: qinyh@scsio.ac.cn)
However, the remote sensing data is confined to the surface information. The lack of subsurface information means that it can be difficult to provide a complete and reasonably accurate description of the large scale ocean state. This has limited ocean research on physical processes. Ocean data assimilation is capable of mostly confirming the ocean state through utilization of acquired information [1]. Thus one way of improving the situation is to develop the global ocean data assimilation system by effectively applying observations to ocean models in conjunction with data assimilation [2], which can produce reasonably accurate reanalysis 
with more complete time-space distribution.

Due to the lack of computing resources, the threedimensional variation (3DVAR) and optimal interpolation (OI) are widely used in the global data assimilation system for real-time operational ocean forecasting [3], such as the Forecasting Ocean Assimilation Model (FOAM) implemented at the UK Met. Office [4], the NCEP Global Ocean Data Assimilation System (GODAS) [5] and the System for Ocean Forecasting and Analyses (SOFA) [6]. In China, the 3DVAR was originally developed by Zhu et al. [7]. Then, Yan et al. [8] introduced the efficient 3DVAR analysisbased method to assimilate observational data sets into the tropical-Pacific circulation model. These observations include temperature data from the expendable bathythermographs (XBT), thermistor data from the Tropical Ocean and Global Atmosphere-Tropical Atmosphere Ocean (TOGATAO) mooring array, sea level anomalies from the TOPEX/ Poseidon and Jason-1 altimetry (T/P-J), and temperature and salinity profiles from the Array for Real-time Geostrophic Oceanography (ARGO) floats. Xiao et al. [9] evaluated a 3DVAR system for the South China Sea (SCS) by assimilating the sea level anomalies TOPEX/Poseidon altimetry. The 3DVAR method was also used in the first generation Global Ocean Data Assimilation System of Beijing Climate Center (BCC_GODAS1.0) [10,11]. However, the observational data assimilated into the BCC_GODAS1.0 is only the temperature field, not including the salinity field. In addition, an experimentally feasible scheme is not proposed to assimilate the satellite remote sensing data in BCC_GODAS1.0. Considering the fact that the climate has changed during recent years [12], it is necessary to develop a new assimilation system with the higher assimilation capacity for meeting modern operating systems needs of studying climate variations. For this reason, Xiao et al. [13], therefore, developed the second generation Global Ocean Data Assimilation System of Beijing Climate Center (BCC_GODAS2.0), which assimilated the ocean data sets of GTS, ARGO floats, NOAA AVHRR, FY-3A and TOPEX/Poseidon into a global ocean model. Compared with the BCC_GODAS1.0, Xiao and her colleagues introduced the techniques of vertical projection [14], recursive filter [15] and nonlinear temperature-salinity relationship [16-18], then developed a new method for assimilating altimeter and SST data under one dynamic constraint based on the 3DVAR.

In this paper, we use this new ocean reanalysis over the period 1990-2009 to examine the impacts of the assimilation result in compare with the simulation without any data assimilation. For verification, different aspects of the fields obtained from the new reanalysis are analyzed and compared with the observational data, which will provide important information to improve the assimilation system performance and ultimately to study and predict climate change impacts.

\section{Assimilation system and data sets}

\subsection{Assimilation system (BCC_GODAS2.0)}

The ocean model used for the BCC_GODAS2.0 is the Modular Ocean Model (MOM.v4, [19]), which is developed and supported by researchers at NOAA's Geophysical Fluid Dynamics Laboratory. The model uses a global tripolar grid. This part of the grid has a single pole over Antarctica. In the Arctic region, the grid places a bipolar region, where the two poles are situated over land. It removes the spherical coordinate singularity present at the geographical North Pole. The resolution in the zonal direction is $1^{\circ}$, while the resolution in the meridional direction is $1 / 3^{\circ}$ within $10^{\circ}$ of the equator, smoothly changing to $1^{\circ}$ in the poleward direction of $30^{\circ}$. There are 50 vertical levels with a $10 \mathrm{~m}$ resolution in the top $225 \mathrm{~m}$. The topography is a montage of that developed by satellite data in the region of $72^{\circ} \mathrm{S}$ to $72^{\circ} \mathrm{N}$ (http://topex.ucsd.edu/marine_topo/mar_topo.html) [20], the NOAA (1988) 5-minute global topography ETOPO5 (http:// www.ngdc.noaa.gov/mgg/global/etopo5.HTML) [21] and the International Bathymetric Chart of the Arctic Ocean (IBCAO, http://www.ngdc.noaa.gov/mgg/bathymetry/arctic/ arctic.html) [22]. The model was forced by monthly mean wind at $10-\mathrm{m}$ level and air temperature at 2-m level from the NCEP-DOE reanalysis 2 [23].

\subsection{Assimilation scheme}

BCC_GODAS2.0 is a 3DVAR-based assimilation system and the control variables are temperature and salinity fields. The assimilation scheme of BCC_GODAS2.0 can be grouped into two steps that are illustrated as follows.

During the first step, the vertical distribution of temperature and salinity are retrieved by assimilating the altimeter data and observational SST datasets along each ground track under the following dynamic constraint [24]:

$$
h(T, S)=-\int_{0}^{Z_{\mathrm{m}}} \frac{\rho(T, S, p)-\rho_{0}(p)}{\rho_{0}(p)} \mathrm{d} z
$$

where $\rho(T, S, p)$ is the equation of state for calculating density; $\rho_{0}(p)=\rho(0,35, p)$ is reference density; $Z_{\mathrm{m}}$ is the reference depth (taken $1000 \mathrm{~m}$ here). The observational SST is projected downward only to the mixed layer. The projection operator can be constructed according to the correlation of SST between observation and model. The correlation coefficient gradually decreases with depth, being set equal to 1 on the sea surface and to 0 at bottom of mixed layer. If the observational SST and SSH are respectively taken into account in the cost function, we have to define their own observation error covariance matrices. When being defined inappropriately, it would introduce additional errors. As a result, the cost function to be minimized is defined by the following: 


$$
\begin{aligned}
J= & \left(T-T_{\mathrm{b}}\right)^{T} B_{T}^{-1}\left(T-T_{\mathrm{b}}\right)+\left(S-S_{\mathrm{b}}\right)^{T} B_{S}^{-1}\left(S-S_{\mathrm{b}}\right) \\
& +\left(h(T, S)+h_{\mathrm{c}}\left(T_{\mathrm{s}}, S\left(T_{\mathrm{b}}\right)\right)-h_{\mathrm{m}}-h_{0}\right)^{T} O^{-1} \\
& \times\left(h(T, S)+h_{\mathrm{c}}\left(T_{\mathrm{s}}, S\left(T_{\mathrm{b}}\right)\right)-h_{\mathrm{m}}-h_{0}\right)
\end{aligned}
$$

where $T$ and $S$ are the vertical temperature and salinity vectors, respectively; $T_{\mathrm{b}}, S_{\mathrm{b}}$ are respectively the corresponding background fields obtained from the model result; $B_{T}, B_{S}$ are the background error covariance matrices in the vertical direction, respectively; $O$ is the observation error covariance matrix; $h_{\mathrm{m}}$ is the mean sea surface height (SSH) of the mod$\mathrm{el} ; h_{0}$ is the observed $\mathrm{SSH}$ anomaly from altimeter data; the dynamic constraint, $h_{\mathrm{c}}$ is calculated from eq. (1) by projecting satellite remote sensing of SST downward.

In the second step, at every model level, the cost function is minimized as follow:

$$
\begin{aligned}
J= & \left(T-T_{\mathrm{b}}\right)^{T} E_{T}^{-1}\left(T-T_{\mathrm{b}}\right)+\left(S-S_{\mathrm{b}}\right)^{T} E_{S}^{-1}\left(S-S_{\mathrm{b}}\right) \\
& +\left(H T-T_{0}\right)^{T} O_{T}^{-1}\left(H T-T_{0}\right) \\
& +\left(H S-S_{0}\right)^{T} O_{S}^{-1}\left(H S-S_{0}\right),
\end{aligned}
$$

where $T$ and $S$ are the temperature and salinity vectors at some level, respectively; $T_{\mathrm{b}}, S_{\mathrm{b}}$ and $E_{T}, E_{S}$ are the background fields and the background error covariance matrices in the horizontal direction, respectively; $O_{T}, O_{S}$ are the observation error covariance matrices of temperature and salinity at the corresponding level; $H$ is the observational bilinear operator which interpolates the model grid to the observation location.

The background error covariance matrix is defined empirically as follows:

$$
B=A \exp \left(-\frac{\Delta x^{2}}{L_{x}^{2}}-\frac{\Delta y^{2}}{L_{y}^{2}}\right),
$$

where $A$ denotes the background error variances of temperature (taken as 2.0) and salinity (0.15); $\Delta x, \Delta y$ are distances between of any two grid points; $L_{x}, L_{y}$ are correlation scales in the east-west and south-north directions, respectively. Here, we take $L_{x}=450 \mathrm{~km}, L_{y}=650 \mathrm{~km}$ for the temperature and $L_{x}=420 \mathrm{~km}, L_{y}=510 \mathrm{~km}$ for the salinity. The observational variances of temperature and salinity are set as 0.1 and 0.05 , respectively. Further details and superiorities of the assimilation scheme can be found in Xiao et al. [13].

\subsection{Data sets}

For this study, we analyzed two sets of the model outputs that cover the period from 1990 to 2009 , one being the assimilation run (BCC_GODAS2.0) and the other being the control run (CTL) without data assimilation. For verification, we examine the annual mean of SST and salinity against the Optimally Interpolated Sea Surface Temperature (OISST, [25]) and the Simple Ocean Data Assimilation (SODA, [26,27]) datasets. In addition, we also analyze the seasonal and interannual variations in the temperature and velocity fields over tropical Pacific by comparing with the $1^{\circ} \times 1^{\circ}$ UK Met Office Hadley Centre Sea Ice and Sea Surface Temperature dataset (HadISST, [28]) and the NCEP Global Ocean Data Assimilation System product (GODAS [5]). To be consistent, we take the OISST, HadISST and NCEP GODAS data sets over the same period of 1990-2009. Anomalies are computed by removing the monthly mean climatology for the above period. The SODA is taken from January 1990 to December 2008 because of its availability.

\section{Results}

The temperature and salinity are the fundamental components of the oceanography, and are the most important parameters for the seawater equation of state, suggesting that they have a closer relation to the other physical property. Consequently, it is significantly important to evaluate an assimilation system whether can improve the prediction of temperature and salinity. In this section, firstly, we will examine the impacts of observations assimilation on the temperature and salinity fields in the sense of the mean state of the global ocean and root mean square error (RMSE). Secondly, validation is judged on the basis of the assimilation system's depiction of both seasonal and interannual variability over tropical Pacific Ocean. The aim was to compare the assimilation result against observations (or other reanalysis), to identify weaknesses and strengths.

\subsection{Analysis-error statistics of the assimilation products}

In order to evaluate the overall performance of the data assimilation system (BCC_GODAS2.0), we present the annual mean bias for temperature and salinity at the surface (Figure 1). For the SST, the maximum SST bias between the CTL and OISST exceeds $4^{\circ} \mathrm{C}$, while the cold SST bias is lowest (below $-3^{\circ} \mathrm{C}$ ) in Northwest Atlantic region (Figure 1(a)). As expected, the problem is overcome to a great extent in the assimilation result, in which the distribution of annual mean SST is in good agreement with that of the OISST, especially in the equatorial eastern Pacific. The SST bias between the BCC_GODAS2.0 and OISST lies in the range $\pm 1^{\circ} \mathrm{C}$ except for some coast regions (Figure 1(b)). It should be noted that the improvement of SST is relative small in the western boundary region in the assimilation result, which may be a result of poorer quality of the satellite data near the coast. For the sea surface salinity (SSS), the bias is somewhat higher in the eastern and central Pacific Ocean, Atlantic Ocean and western Indian Ocean, with the largest value exceeding 2 psu (Figure 1(c)). After assimilating all kinds of observations, the SSS bias between the BCC_GODAS2.0 and SODA is reduced, ranging within 

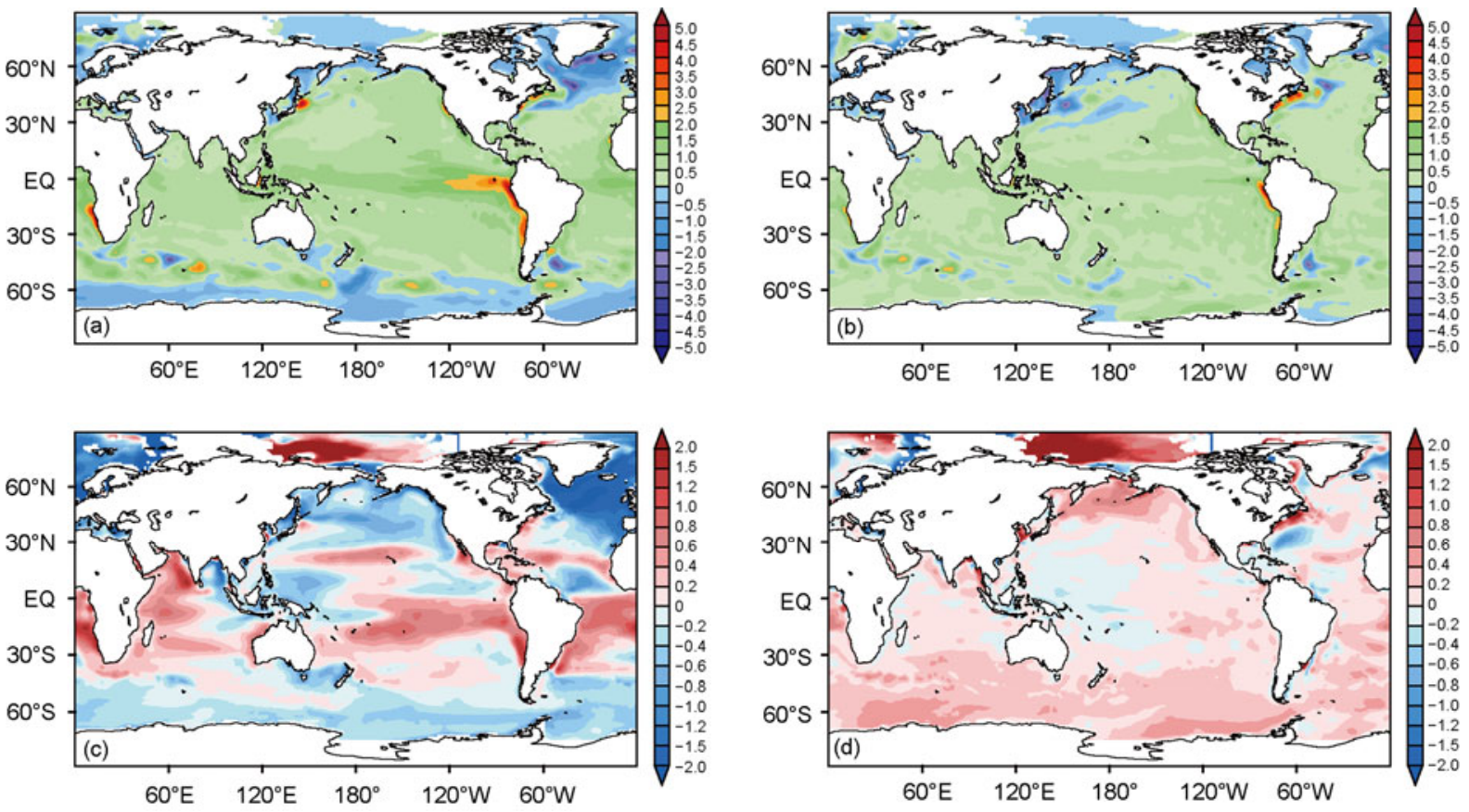

Figure 1 Distributions of SST bias $\left({ }^{\circ} \mathrm{C}\right.$ ) and SSS bias (psu) averaged from 1990-2009. (a) CTL SST and OISST; (b) BCC_GODAS2.0 SST and OISST; (c) CTL SSS and SODA SSS; (d) BCC_GODAS2.0 SSS and SODA SSS.

\pm 0.5 psu (Figure 1(d)). Maybe due to both the model bias itself and the scarcity of observational data in high latitudes, the SSS bias is still large in Arctic Siberia after data assimilation. Besides, the model is force with climatological river runoff data, and is not being considered the effect of freshwater forcing on salinity, which, to some degree, contributes to the SSS bias in these regions.

Figure 2 shows standard deviation (STD) distributions of SST and SSS to reflect interannual variability. A large STD of SST is seen in regions of western boundary current extensions (Kuroshio and Gulf Stream), equatorial eastern Pacific Ocean and along the $30^{\circ} \mathrm{S}$ latitude (Figure 2(a), (c) and (e)). Compared with CTL, the amplitude of STD in BCC_GODAS2.0 is more similar to OISST in equatorial eastern Pacific Ocean. By contrast, SSS interannual variability is weak, with the large STD in the Arctic region. The SSS in CTL shows weaker variability in Arctic than that in SODA, but stronger in tropical Pacific and Indian Ocean. This situation is improved drastically in these regions after assimilation (Figure 2(b), (d) and (f)).

Figure 3 shows the vertical distribution of RMSE relative to the SODA data. Here, SST is replaced by OISST because it incorporates in situ observations as well as satellite-based observations. On the whole, the improvement of temperature and salinity is very significant. For the temperature (Figure 3(a)), the assimilation result produces improvement obviously in the subsurface ocean, with a maximum of $1.05^{\circ} \mathrm{C}$. The overall RMSE is reduced by $0.53^{\circ} \mathrm{C}$ compared to that of CTL. For the salinity (Figure 3(b)), the RMSE of BCC_GODAS2.0 is reduced by 0.40 psu at most, with averaged RMSE of 0.28 psu. Compared with $\mathrm{BCC}_{-}$ GODAS1.0, the RMSE estimations of BCC_GODAS2.0 for temperature and salinity have a certain improvement at each level. Similar to Xiao et al. [13], it is indicated that assimilation of satellite remote sensing data can effectively improve both temperature and salinity estimations. We also note that the overall RMSE estimations for temperature and salinity exceed the NCEP GODAS by $0.35^{\circ} \mathrm{C}$ and $0.14 \mathrm{psu}$, respectively.

\subsection{Temperature variation over tropical Pacific Ocean}

The RMSE only shows the overall improvement for temperature and salinity, not showing detailed variations at some local areas, such as in the tropical Pacific Ocean, where ENSO is the most important mode of variability in the present climate and dominates the interannual variability of the coupled ocean atmosphere interactions. In the following section we continue to further evaluate the performance of BCC_GODAS2.0 in tropical Pacific by comparing with the observational data (HadISST) and the NCEP GODAS.

The seasonal cycle is a prominent mode of climate variability in tropical Pacific Ocean and exerts a significant control over the dynamics of ENSO [29], so seasonal variations in SST along the equator $\left(2^{\circ} \mathrm{S}-2^{\circ} \mathrm{N}\right)$ are presented by subtracting the annual mean (Figure 4). It is obvious from the figure that seasonal variations in SST from the $\mathrm{BCC}_{-}$ GODAS2.0 correspond well to those of HadISST along the equator, being strong in the central and eastern Pacific but 

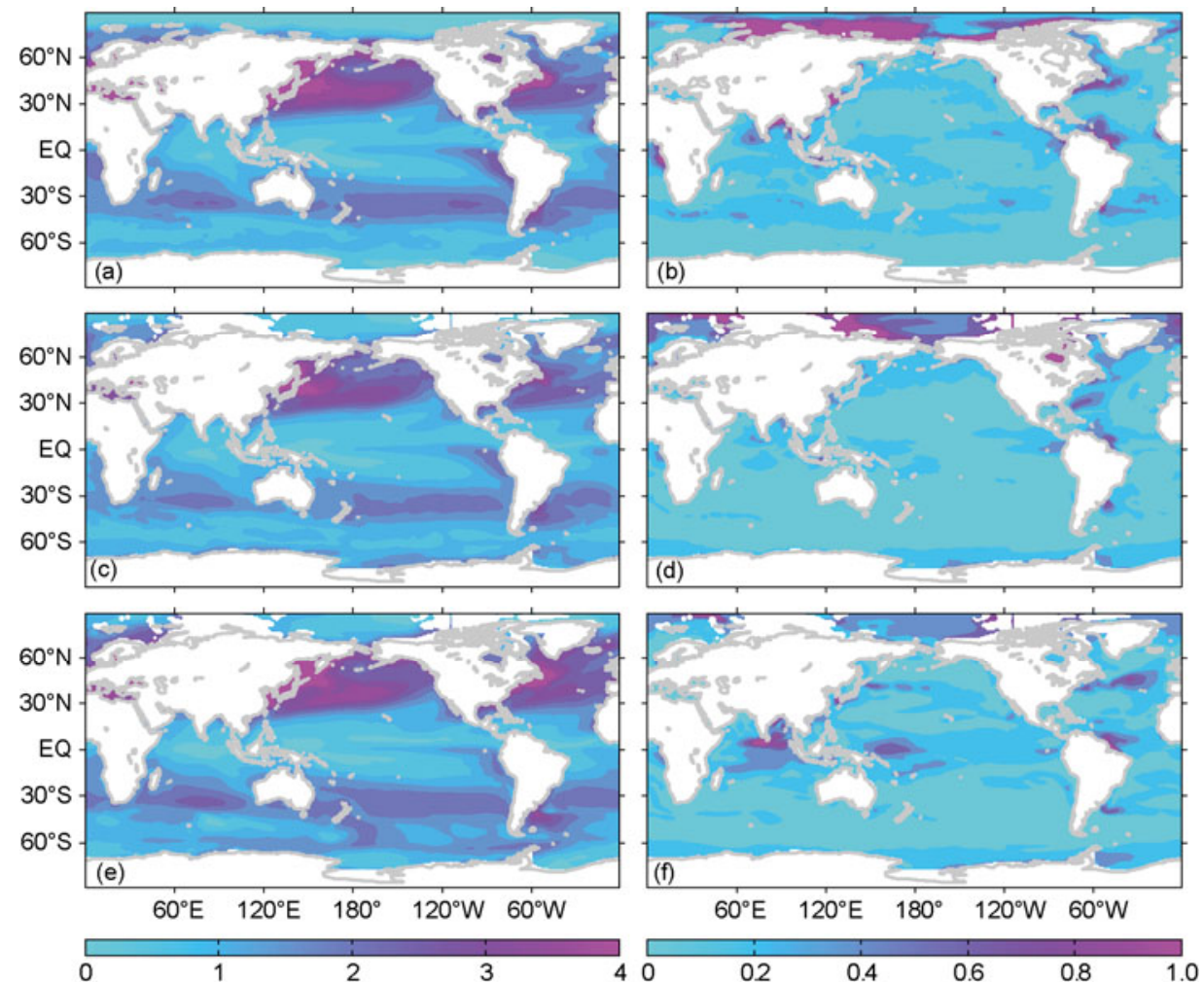

Figure 2 Standard deviation of SST (left panels, ${ }^{\circ} \mathrm{C}$ ) and SSS (right panels, psu). (a) OISST; (b) SODA; (c)-(d) BCC_GODAS2.0; (e)-(f) CTL.
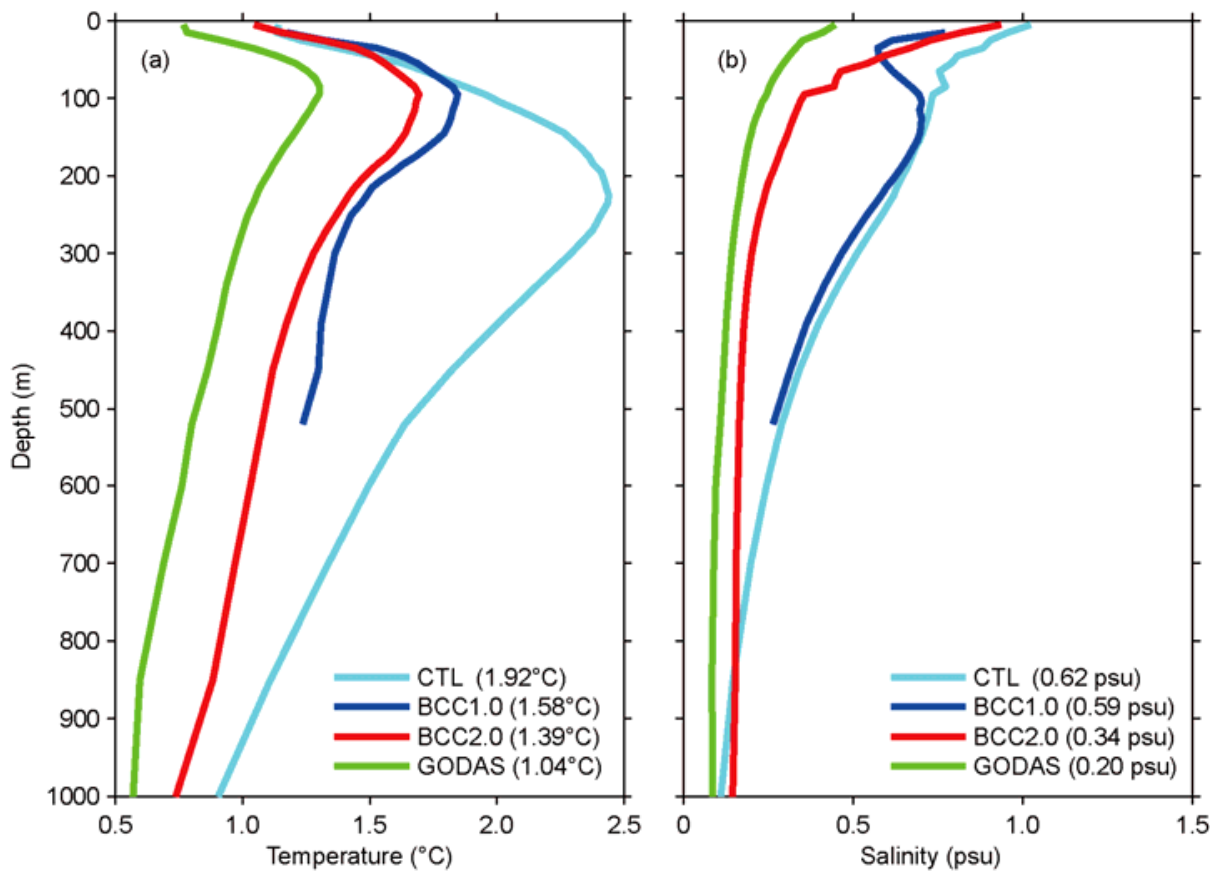

Figure 3 Vertical distribution of RMSE for temperature (a) and salinity (b) for the period 1990-2009. The numbers in brackets indicate overall RMSE.

weak in the western Pacific. In addition, the clear westward propagation of dominant annual period fluctuation is represented well in BCC_GODAS2.0, with warm SST in spring (March and April) and cold SST in autumn (September and Octobber). With regard to amplitude, BCC_GODAS2.0 has a maximum of warm SST $\left(2.49^{\circ} \mathrm{C}\right)$ slightly lower than that of HadISST $\left(2.75^{\circ} \mathrm{C}\right)$, and has a minimum below $-2.0^{\circ} \mathrm{C}$ (about $-1.94^{\circ} \mathrm{C}$ in HadISST). We further plot the STD of monthly SST anomalies averaged over the area $2^{\circ} \mathrm{S}-2^{\circ} \mathrm{N}$ as a function of longitude and calendar month. As is shown in 

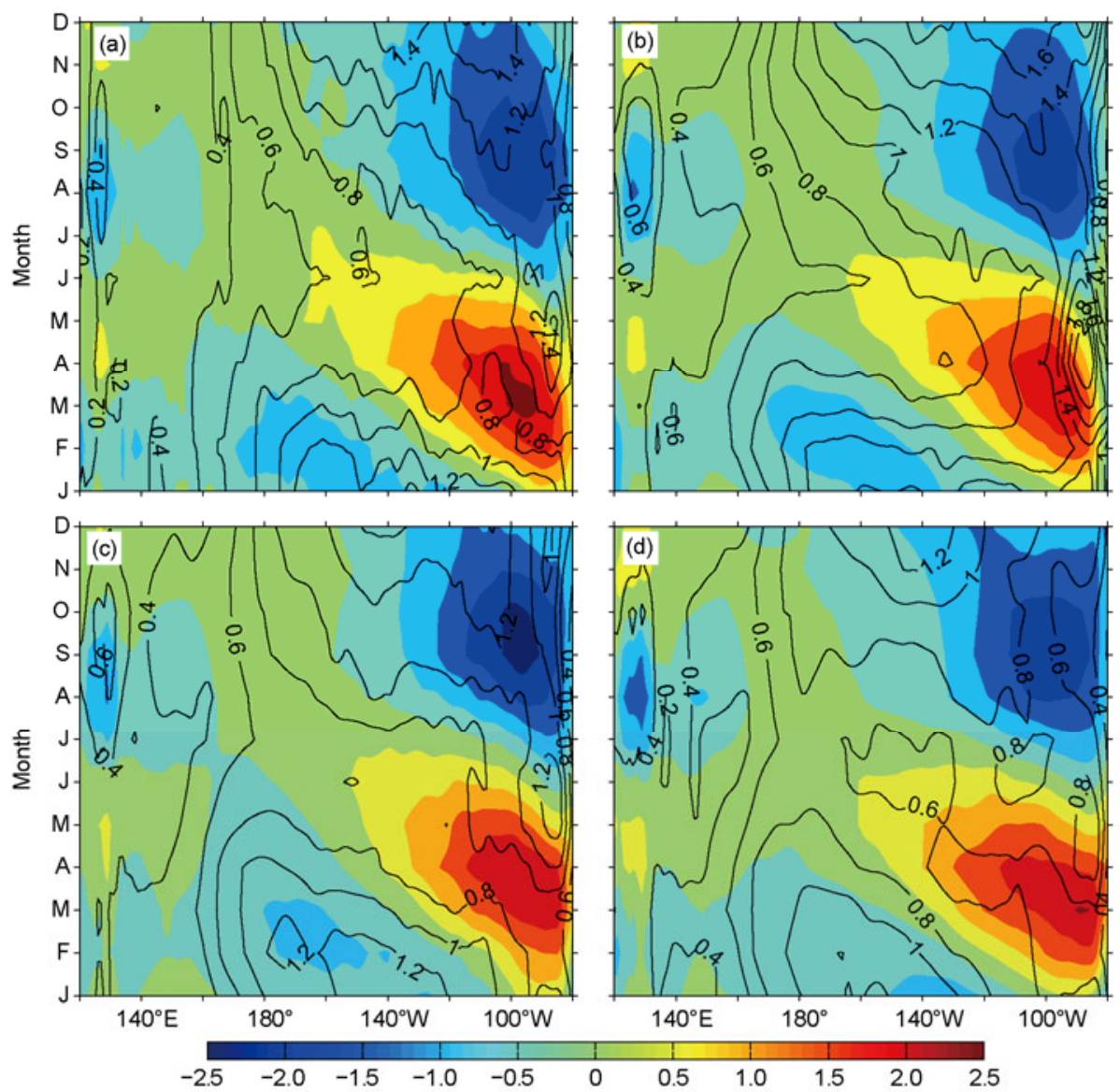

Figure 4 Seasonal cycle of SST (annual mean removed) averaged over $2^{\circ} \mathrm{S}-2^{\circ} \mathrm{N}$ along the equator (shaded) and the standard deviation of SST anomalies as a function of longitude and month (contours). (a) HadISST; (b) NCEP GODAS; (c) BCC_GODAS2.0; (d) CTL.

Figure 4, the variance of SST anomalies in $\mathrm{BCC}_{-}$ GODAS2.0 has a pronounced seasonal cycle in the equatorial eastern Pacific $\left(140^{\circ}-100^{\circ} \mathrm{W}\right)$, being largest in autumn and early winter and smallest in spring, which may explain why the prediction skill decreases greatly in boreal spring in some dynamic prediction models of ENSO [30]. It is worth noting that the amplitude of the STD in BCC_GODAS2.0 is much closer to that of HadISST than the NCEP GODAS does.

Figure 5 displays the longitude-depth distributions of temperature and zonal current along the equator $\left(2^{\circ} \mathrm{S}-2^{\circ} \mathrm{N}\right)$ from the NCEP GODAS, BCC_GODAS2.0 and CTL, respectively. These three analyses show similar large zonalscale features, such as the decreased thermocline depth $\left(20^{\circ} \mathrm{C}\right.$ isotherm) from the west to the east, caused by the slow accumulation of warm water in the western Pacific in response to the trade winds [31]. With regard to the eastward Equatorial Undercurrent (EUC) of NCEP GODAS, the core from each month slopes upward toward the east along the thermocline depth with maximum flow around $140^{\circ} \mathrm{W}$. The variations of the EUC in BCC_GODAS2.0 are similar to those of NCEP GODAS, including the location of maximum value, but there are some differences in strength. The magnitude maxima of the assimilation system varies largely in different months, from about $45.5 \mathrm{~cm} / \mathrm{s}$ in April to 37.8 $\mathrm{cm} / \mathrm{s}$ in October (Figure 5(b) and (e)), compared respectively with the $77.0 \mathrm{~cm} / \mathrm{s}$ and $48.1 \mathrm{~cm} / \mathrm{s}$ of the NCEP GODAS currents (Figure 5(a) and (d)).

We turn now to analyze the interannual variability of monthly SST anomalies over tropical Pacific. Since interannual variations are associated with El Niño activity, represented by the Niño3 index (averaged SST anomalies over $5^{\circ} \mathrm{S}-5^{\circ} \mathrm{N}, 150^{\circ}-90^{\circ} \mathrm{W}$ ), the time series of Niño3 index for the period January 1990 to December 2009 is shown below (Figure 6). Generally, these three time series show significant interannual fluctuations during the study period. The Niño3 index for BCC_GODAS2.0 corresponds well to that obtained from HadISST, both in amplitude and phase. The correlation coefficient between CTL and HadISST is 0.92, with corresponding RMSE of $0.41^{\circ} \mathrm{C}$. They are respectively improved to 0.94 and $0.36^{\circ} \mathrm{C}$ after assimilating real observations. Further, we carry out an empirical orthogonal function (EOF) analysis to evaluate climate modes of variability over tropical Pacific $\left(30^{\circ} \mathrm{S}-30^{\circ} \mathrm{N}, 120^{\circ} \mathrm{E}-80^{\circ} \mathrm{W}\right)$. The dominant two EOF modes of the monthly SST anomaly are presented in Figure 7. The EOF1 mode of HadISST shown in 


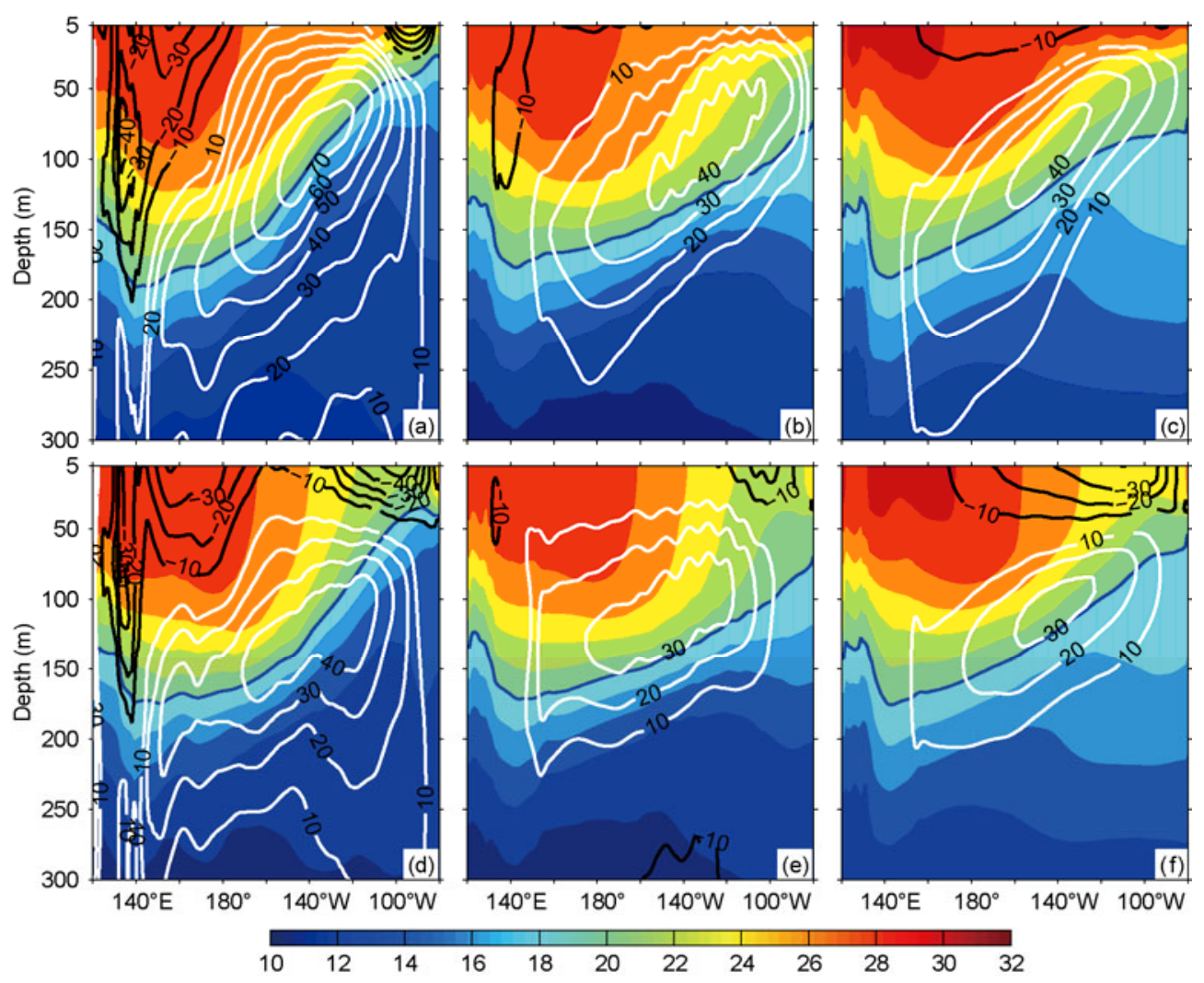

Figure 5 Longitude-depth distributions of temperature (shaded, ${ }^{\circ} \mathrm{C}$ ) and zonal current (contours, $\mathrm{cm} / \mathrm{s}$ ) along the equator $\left(2^{\circ} \mathrm{S}-2^{\circ} \mathrm{N}\right)$ in April (upper panels) and October (lower panels) from (a), (d) NCEP GODAS, (b), (e) BCC_GODAS2.0 and (c), (f) CTL, respectively. The black lines indicate westward flow, white lines indicate eastward flow and blue lines indicate the $20^{\circ} \mathrm{C}$ isotherm depth.

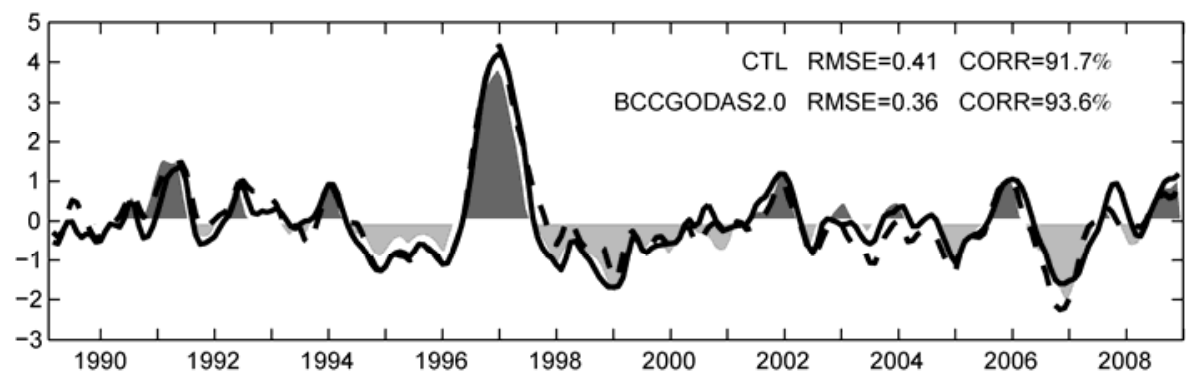

Figure 6 The time series of Niño3 index of HadISST (shadow), BCC_GODAS2.0 (solid line) and CTL (dash line) during the period from January 1990 to December 2009. The RMSE and CORR represent the root mean square error and correlation coefficients, respectively.

Figure 7(a) captures the traditional El Niño pattern, characterized by anomalous warming in the eastern equatorial Pacific Ocean, while anomalous cooling appears in the western Pacific Ocean [32]. This pattern explains around $51.3 \%$ of the tropical Pacific SST anomaly interannual variability for the period 1990-2009. For the EOF1 of BCC_ GODAS2.0 that explains $41.6 \%$ of the total interannual SST anomaly variance (Figure 7(c)), the magnitudes of positive loadings in the equatorial eastern Pacific are relative weaker than that of HadISST, but have an increase above $0.3^{\circ} \mathrm{C}$ compared with CTL, indicating that assimilating observations can improve the SST anomaly variability in the cold tongue region. The EOF2 pattern of HadISST
(Figure 7(b)), explaining $15.2 \%$ of the SST anomaly variance, exhibits the El Niño Modoki pattern [33], which shows a warming horseshoe pattern over the central equatorial Pacific with cold centers on both sides of the warm center along the equator. Comparatively, the EOF2 pattern of BCC_GODAS2.0 extends more strongly toward the north subtropics, but less toward the south subtropics (Figure 7(d)). More importantly, it overcomes the problem that negative loadings are confined in the narrow equatorial eastern Pacific (Figure 7(f)). Consequently, the magnitude and spatial distribution of the leading EOF patterns of BCC_GODAS2.0 are well consistent with those of HadISST. 
(a) EOF1 $51.3 \%$

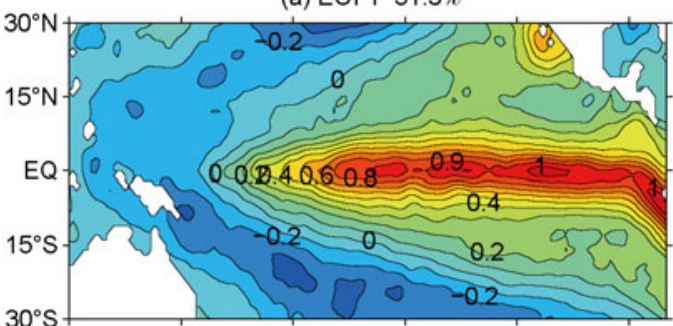

(c) EOF1 $41.6 \%$

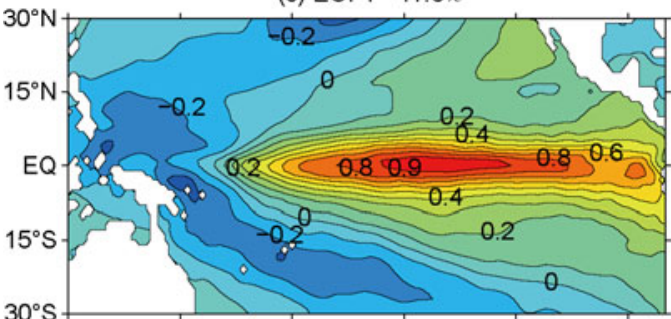

(e) EOF1 $42.4 \%$

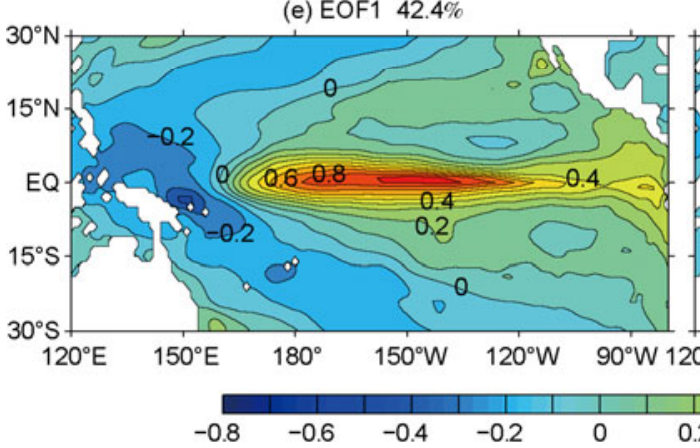

(b) EOF2 $15.2 \%$

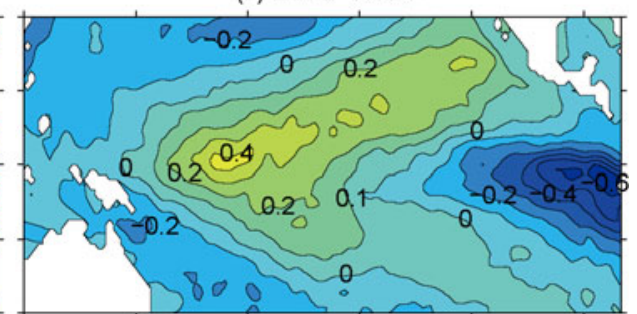

(d) EOF2 $15.1 \%$

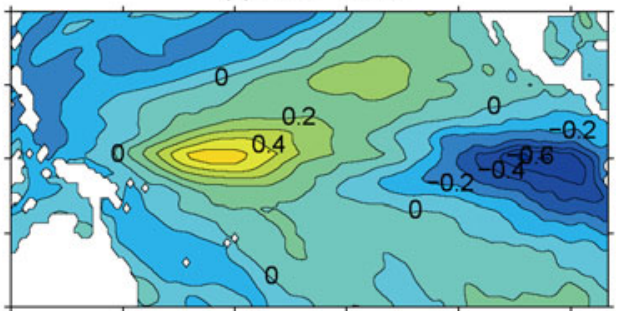

(f) EOF2 $14.8 \%$

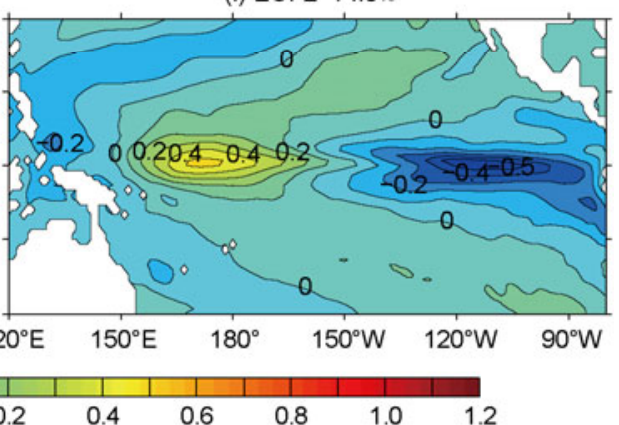

Figure 7 The first (left panels) and second (right panels) EOF modes of tropical Pacific SST anomalies (1990-2009) multiplied by respective standard deviations of the principal components. The numbers at the top indicate the corresponding explained variances. (a), (b) HadISST; (c), (d) BCC_GODAS2.0; (e), (f) CTL.

\section{Conclusions}

We present some preliminary results from a new ocean reanalysis for the period 1990-2009 to evaluate performances of the assimilation system (BCC_GODAS2.0) by comparing with the OISST, HadISST, SODA and NCEP GODAS datasets. The main conclusions are as follows:

(1) On the whole, the assimilation result may effectively improve both temperature and salinity estimations, especially in the equatorial eastern Pacific. By comparison with the OISST and SODA, the RMSE estimations of temperature and salinity are reduced by $0.53^{\circ} \mathrm{C}$ and $0.28 \mathrm{psu}$, respectively.

(2) The results of tropical Pacific Ocean show that the assimilation result produces more distinguished improvements. Variations in SST from the BCC_GODAS2.0 are represented well the large scale features in the equatorial Pacific, such as strong magnitude of seasonal cycle in the central and eastern Pacific and weak magnitude in the western Pacific, and the westward propagation of the annual period fluctuations, with warm SST in spring and cold SST in autumn. The amplitude of the STD in BCC_GODAS2.0 is much close to HadISST than the NCEP GODAS does.
Additionally, The BCC_GODAS2.0 qualitatively reproduces variations of the EUC, but with weak magnitude. Besides, the positive interannual variations of EOF1 pattern of $\mathrm{BCC}_{-}$ GODAS2.0 are improved by $0.3^{\circ} \mathrm{C}$ in the equatorial eastern Pacific compared with CTL. The EOF2 pattern solves the problem that negative loadings are confined in the narrow equatorial eastern Pacific, making the magnitude and spatial distribution close to the observations (HadISST).

In summary, the new ocean reanalysis (BCC_GODAS2.0) shows a significant improvement relative to CTL. There some problems in the reanalysis, such as limited improvement in mid-latitudes and large salinity bias in high latitudes, so some efforts are needed to continue to improve the assimilation system. The temporal and spatial characteristics of El Niño and El Niño Modoki will be discussed further in another paper.

This work was supported by the National Basic Research Program of China (2011CB403504 and 2011CB403505).

1 Talagrand O. Assimilation of observations: An introduction. J Meteor Soc Jpn, 1997, 75: 191-209

2 You X B, Zhou G Q, Zhu J, et al. Sea temperature data assimilation 
system for the China Sea and adjacent areas. Chin Sci Bull, 2003, 48: 70-76

3 Shu Y Q, Wang D X, Zhu J, et al. The 4-D structure of upwelling and Pearl River plume in the northem South China Sea during summer 2008 revealed by a data assimilation model. Ocean Model, 2011, 36: 228-241

4 Bell M J, Forbes R M, Hines A. Assessment of the FOAM global data assimilation system for real-time operational ocean forecasting. $\mathrm{J}$ Mar Syst, 2000, 25: 1-22

5 Behringer D W, Ji M, Leetmaa A. An improved coupled model for ENSO prediction and implications for ocean initialization. Part I: The ocean data assimilation system. Mon Weather Rev, 1998, 126: 1013-1021

6 De Mey P, Benkiran M. A multivariate reduced-order optimal interpolation method and its application to the Mediterranean basin-scale circulation, In: Pinardi N, Woods J, eds. Ocean Forecasting, Conceptual basis and Applications. Berlin: Springer-Verlag, 2002

7 Zhu J, Zhou G Q, Yan C, et al. A three-dimensional variational ocean data assimilation system: Scheme and preliminary results. Sci China Ser D-Earth Sci, 2006, 49: 1212-1222

8 Yan C X, Zhu J, Zhou G Q. Impacts of XBT, TAO, altimetry, and ARGO observations on the tropic Pacific Ocean data assimilation. Adv Atmos Sci, 2007, 24: 383-398

9 Xiao X J, Wang D X, Yan C X, et al. Evaluation of a 3dVAR system for the South China Sea. Prog Nat Sci, 2008, 18: 547-554

10 Liu Y M, Zhang R H, Yin Y H, et al. The application of ARGO data to the global ocean data assimilation operational system of NCC. Acta Meteor Sin, 2005, 29: 355-365

11 Liu Y M, Li W J, Zhang P Q. A global 4-dimensional ocean data assimilation system and the studies on its results in the tropic Pacific (in Chinese). Acta Oceanol Sin, 2005, 27: 27-35

12 Li X Y, Qin D H, Xiao C D, et al. Progress regarding climate change during recent years (in Chinese). Chin Sci Bull (Chin Ver), 2011, 56: 3029-3040

13 Xiao X J, He N, Zhang Z Q, et al. Variation assimilation using satellite data of sea surface temperature and altimeter (in Chinese). J Trop Oceanogr, 2011, 30: 1-8

14 Haines K. A direct method for assimilating sea surface height data into ocean models with adjustments to the deep circulation. J Phys Oceanogr, 1991, 21: 843-868

15 Hayden C M, Purser R J. Recursive filter objective analysis of meteorological fields: Applications to NESDIS operational processing. $\mathrm{J}$ Appl Meteor, 1995, 34: 3-15

16 Troccoli A, Haines K. Use of the temperature-salinity relation in a data assimilation context. J Atmos Oceanic Technol, 1999, 16: 2011-2025
17 Yan C X, Zhu J, Li R, et al. Roles of vertical correlation of the background error and T-S relation in estimation temperature and salinity profiles from sea surface dynamic height. J Geophys Res, 2004, 109: C08010

18 Zhu J, Yan C X. Nonlinear balance constraints in 3DVAR data assimilation. Sci China Ser D-Earth Sci, 2006, 49: 331-336

19 Griffies S M, Harrison M J, Pacanowski R C, et al. A Technical Guide to MOM4, 2003. 295

20 Smith W H F, Sandwell D T. Global seafloor topography from satellite altimetry and ship depth soundings. Science, 1997, 277: 19571962

21 Edwards M O. Global gridded elevation and bathymetry (ETOPO5), digital raster data on a 5-minute geographic (lat/lon) $2160 * 4320$ (centroid-registeredg) grid. Boulder, NOAA Natl Geophys Data Cent, 1989

22 Jakobsson M, Macnab R, Mayer L, et al. An improved bathymetric portrayal of the Arctic Ocean: Implications for ocean modeling and geological, geophysical and oceanographic analyses. Geophys Res Lett, 2008, 35: L07602

23 Kanamitsu M, Ebisuzaki W, Woollen J, et al. NCEP-DOE AMIP- II Reanalysis (R-2). Bull Amer Meteor Soc, 2002, 83: 1631-1643

24 Gill A E, Niiler P P. The theory of the seasonal variability in the ocean. Deep-Sea Res, 1973, 20: 141-177

25 Reynolds R W, Rayner N A, Smith T M, et al. An improved in situ and satellite SST analysis for climate. J Clim, 2002, 15: 1609-1625

26 Carton J A, Chepurin G, Cao X, et al. A simple ocean data assimilation analysis of the global upper ocean 1950-95. Part I: Methodology. J Phys Oceanogr, 2000, 30: 294-309

27 Carton J A, Chepurin G, Cao X, et al. A simple ocean data assimilation analysis of the global upper ocean 1950-95. Part II: Results. J Phys Oceanogr, 2000, 30: 311-326

28 Rayner N A, Parker D E, Horton E B, et al. Global analyses of sea surface temperature, sea ice, and night marine air temperature since the late nineteenth century. J Geophys Res, 2003, 108: 4407

29 Xie S P. Interaction between the annual and interannual variations in the equatorial Pacific. J Phys Oceanogr, 1995, 25: 1930-1941

30 Webster P J, Yang S. Monsoon and ENSO: Selectively interactive systems. Quart J Roy Meteor Soc, 1992, 118: 877-926

31 Wyrtki K. Water displacements in the Pacific and the genesis of El Niño cycles. J Geophys Res, 1985, 90: 7129-7132

32 Rasmusson E M, Carpenter T H. Variations in tropical sea surface temperature and surface wind fields associated with the Southern Oscillation/El Niño. Mon Weather Rev, 1982, 110: 354-384

33 Ashok K, Behera S K, Rao S A, et al. El Niño Modoki and its possible teleconnection. J Geophys Res, 2007, 112: C11007

Open Access This article is distributed under the terms of the Creative Commons Attribution License which permits any use, distribution, and reproduction in any medium, provided the original author(s) and source are credited. 